\title{
6.2 The study of the ability of soy isolates of different trademarks to interact with water molecules
}

Plant proteins are used in many areas of the food industry because they have properties, which are necessary to stabilize the quality of combined food products and lower cost compared to alternative additives of animal origin, such as milk powder, casein, egg white and egg yolk, gelatin. In addition, plant proteins (their concentrates and isolates) have a number of functional properties, such as emulsifying, stabilizing, water-binding, texture-forming abilities, absorption of fat and water, etc. [305].

Cereals and legumes (especially soybeans) are still one of the most important resources of plant proteins for food purposes. The most promising raw materials for the production of protein preparations are legumes - peas, beans, lentils, chickpeas, lupines, the protein content of which ranges from 18 to $40 \%$ [306].

Soy isolates are a unique plant protein preparation: the mass fraction of protein in them is $92-95 \%$, which is easily absorbed by the body. A special advantage of soy protein isolate is its ability to form gel, including when it is heated. In terms of functional properties, soy isolate is close to muscle proteins. It is used for technological purposes in the manufacture of sausages, to replace expensive myofibrillar muscle protein, in the production of emulsions from low-grade and frozen raw meat materials [307].

The range of protein isolates is constantly increasing. New types of these drugs are conventionally divided into two groups. The first group includes isolates which molecular properties are modified as a result of changes in the degree of ionization the proteins ionic groups during the formation of different salts, as well as when mixing isolates with various additives (emulsifiers, vitamins, mineral salts). The second group includes isolates which molecular weight is modified by enzymatic or chemical hydrolysis. The functional properties of protein isolates are determined by their average molecular weight, the depth of hydrolysis, the nature and degree of ionization and the chemical nature of the used additives [308].

Technologically, soy isolate is perfectly combined with meat raw materials as it behaves like low-fat types of meat and has an increased water-binding capacity, 
emulsifying properties and forms strong gels. The effect of high temperatures does not impair the functional and technological properties (FTP) of the soy product. The homogeneity of the chemical composition of soy isolate makes it easy to predict the nature of technological changes in meat emulsions when using it [309].

Studies have shown that FTP of soy protein preparations were similar to the structure-forming muscle proteins of lean meat.

The production of highly concentrated protein preparations (isolates and concentrates) is concentrated at factories in the USA, Western Europe, Japan and Israel. In recent years, own production of concentrates and isolates has been actively developing in China and India. The leading manufacturers are Archer Daniels Midland (ADM, USA) and Proteir Techology International (PTI, USA), Moguntsiya (Germany), and Central Soya (Denmark).

Now the creation of competitive meat products is currently inextricably linked with the use of protein preparations. This allows to stabilize the protein matrix, emulsify fat with water and facilitate its incorporation into this matrix, increase the protein content in the product when using meat raw materials with a low protein content, improve the nutritional and biological value of the finished product, increase its yield, stabilize the technological process and increase the economic production efficiency [309].

High functional and technological properties of soy protein isolates in combination with increased biological value, multivariance of technological applications, high economy efficiency and ease of use allow to consider this type of additive to be the most promising for implementation in meat production, as evidenced by the experience of 45 countries. Therefore, rational approaches and justification for the choice of this ingredient is an important task for the food industry.

Currently, there are many studies of Ukrainian and foreign scientists in the direction of studying the main FTP and structural and mechanical properties (SMP) of soy isolates [307,308,310,311]. However, taking into account the constant updating of soy isolates' assortment at the Ukrainian market for their selection, when used in the manufacture of food products, it is advisable to study the properties of the main brands. 
For this purpose, after analyzing the Ukrainian market, the following representatives were selected: soy isolate of TM "SOYPRO 900E" (Soypro) for sausage production, LLC "Raw Material Company of Ukraine", country of origin: China; soy isolate of TM "Maysol", manufacturer: Moguntsia-Interrus, Russia; soy isolate 90\% Solae Supro 500E, company manufacturer: Solae, USA; soy isolate GS 5000, manufacturer: Gushen, China; soy isolate (Harbin Hi-Tech), manufacturer: Harbin Hi-Tech, Poland (TD "Industrial Chemistry in Ukraine", Ukraine).

According to the specification for soy isolates, it is recommended to use them in the production of emulsified and coarsely ground fish and meat products of various categories, dairy products, bakery, flour confectionery products, soups, sauces, yogurts, dry drinks, baby food and dietary foods; boiled sausages, frankfurters, sausages and meat loaves - of premium, first and second grades; semi-smoked, boiledsmoked and smoked sausages; chopped semi-finished products (cutlets, hamburgers, meatballs, minced meat, dumplings, etc.); crab sticks, canned meat. It is recommended to add them to the minced meat systems in dry form, in hydrated form (hydration degree 1:6), in the form of protein-fat emulsion 1:6:6/protein-fat-water and in the form of granules (isolate / water 1:3.5).

To establish and confirm the possibility of using soy isolates in food products, to determine the amount of their application and for recommendations for the choice of a rational protein preparation, a complex of FTP and SMP of soy isolates of selected brands was studied. Additionally, the effect of nanocomposite on the change of the main FTP and SMP of soy preparations was studied. In the studies nanocomposites (amorphous silicon dioxide (Aerosil) E551 brand A-300), synthesized by specialists of amorphous structures and structurally ordered oxides named after A.A. Chuiko NAS of Ukraine with a specific surface area $\mathrm{S}_{\mathrm{BET}}=232 \mathrm{~m}^{2} / \mathrm{g}$, and the corresponding average radius of the primary nanoparticles $-5.88 \mathrm{~nm}$ and the bulk density $-\rho_{0} \approx 22 \mathrm{~g} / \mathrm{cm}^{3}$ were used. Based on the literature review and previous studies of the effect of this additive on raw meat proteins, the amount of application was $0.3 \%$ by weight of the hydration system [312, 313, 314, 315]. 
Studies of such FTP indicators as water-absorbing (WAC) and water-holding capacity (WHC) were performed for dry powdered soy isolates of different brands without pre-hydration.

Water-absorbing (WAC) and water-holding capacity (WHC) were determined by centrifugation according to the methods [316, 317] with certain modifications. Experimental samples weighing $0.5 \mathrm{~g}$ were dispersed in $50 \mathrm{ml}$ of distilled water, placed in weighed centrifuge tubes and left for $30 \mathrm{~min}$ at room temperature and weighed, then centrifuged for $30 \mathrm{~min}$ at $3500 \mathrm{rpm}$. To determine the WHC before centrifugation, the tubes were subjected to heat treatment for 30 min (stirring constantly) to a temperature in the center of $70 \pm 2{ }^{\circ} \mathrm{C}$. Then they were cooled to a temperature of $10 \pm 2{ }^{\circ} \mathrm{C}$ and centrifuged. The upper layer with water was removed and dried for $25 \mathrm{~min}$ at $50{ }^{\circ} \mathrm{C}$ to remove excess moisture. Then it was re-weighed. WAC and WHC was expressed in $\mathrm{ml}$ of the absorbed (retained) water / $\mathrm{g}$ of the dry sample which was defined by the formula:

$$
\mathrm{WHC}(\mathrm{WAC})=\left(\mathrm{W}_{2}-\mathrm{W}_{1}\right) / \mathrm{W}_{0}
$$

where $\mathrm{W}_{2}$ - the mass of the test tube with the sample after centrifugation; $\mathrm{W}_{1}-$ the mass of the test tube with a dry experimental sample; $\mathrm{W}_{0}$ - the mass of the dry sample.

The main characteristics which are one of the crucial factors when choosing ingredients for the meat industry are the ability to absorb water and retain it during heat treatment. Therefore, for the selected brands of soy isolates, the indicators of WAC and WHC were investigated, the results of which are presented in Figures 1 and 2. 


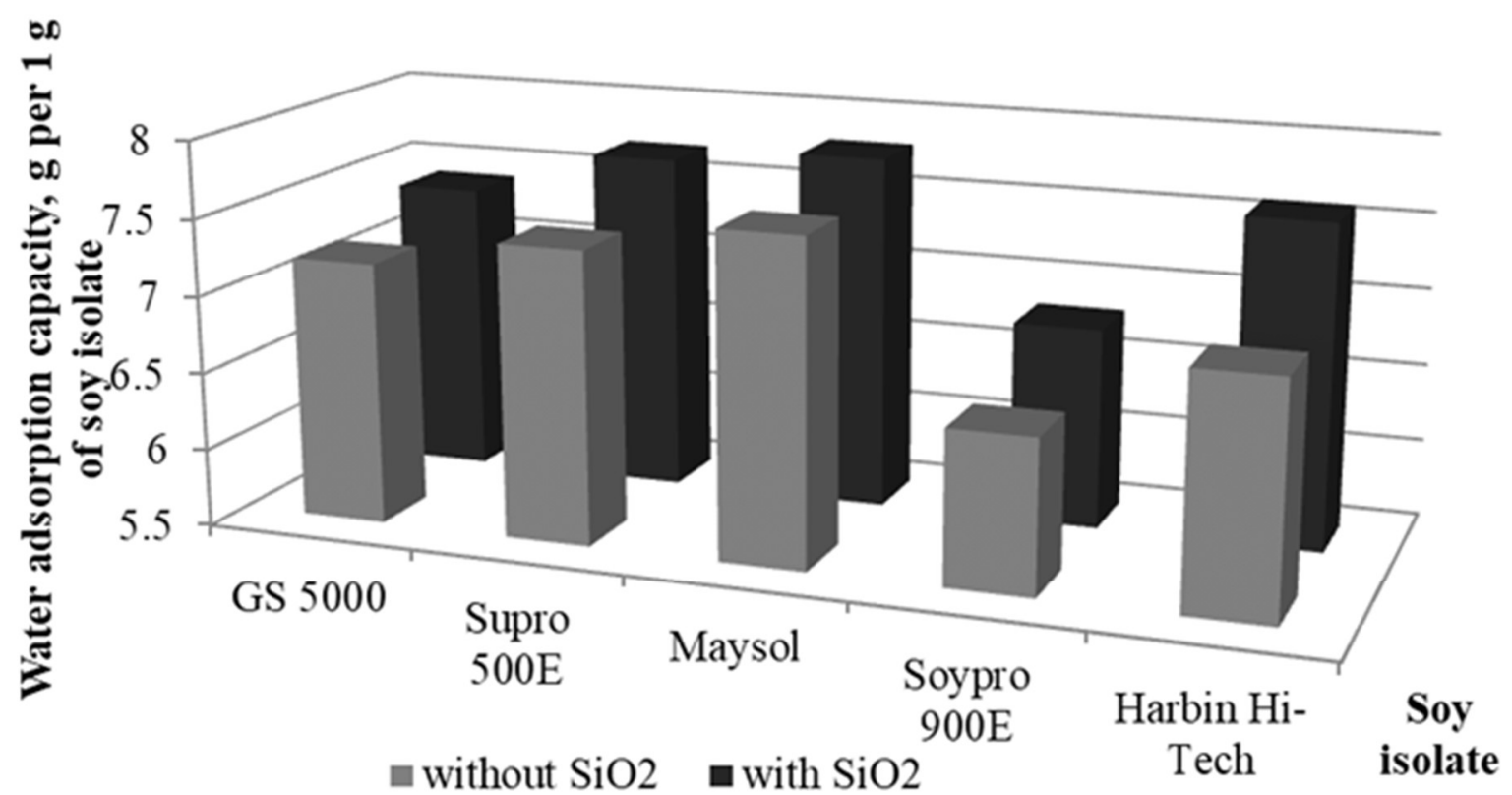

Notation: $\mathrm{SiO}_{2}$ - pyrogenic silica in the nanocomposite form (brand "Aerosil" A300), food additive E551.

Figure 1. Water-absorbing capacity of soy isolates of selected brands

WAC characterizes mainly the ability of proteins of experimental samples to physically interact with water molecules. Analysis of the presented data (Fig. 1) allowed to establish the benefits of the ability to absorb water for soybean isolate Maysol. For soy isolates of Supro 500E, GS 5000 and Harbin Hi-Tech brands, this indicator was lower by $2-8 \%$ compared to the protein preparation Maysol. The lowest rate of WAC was for protein isolate of plant origin of SOYPRO 900E brand. The introduction of nanocomposite (silica) to soy isolates helped to improve their water absorption capacity by 3-9\%. The highest manifestation of synergistic properties was observed in the interaction of Harbin Hi-Tech soy isolate with pyrogenic silica (WAC increased by $9 \%$ compared to this value for pure soy isolate).

The WHC allowed to assess the change in the properties and / or structure of proteins under the influence of temperature, which was manifested in the modification of the relationship with respect to water molecules. The WHC indicator of soy isolates (Fig. 2) allowed to establish the ability of proteins to retain absorbed water after heat treatment. For soybean isolates of GS 5000, Harbin Hi-Tech brands the highest level of water holding was noted, which was higher by $4-6 \%$ compared to the WAC of these 
isolates. For other soy isolates, in comparison with these isolates, WHC was 4-11\% less.

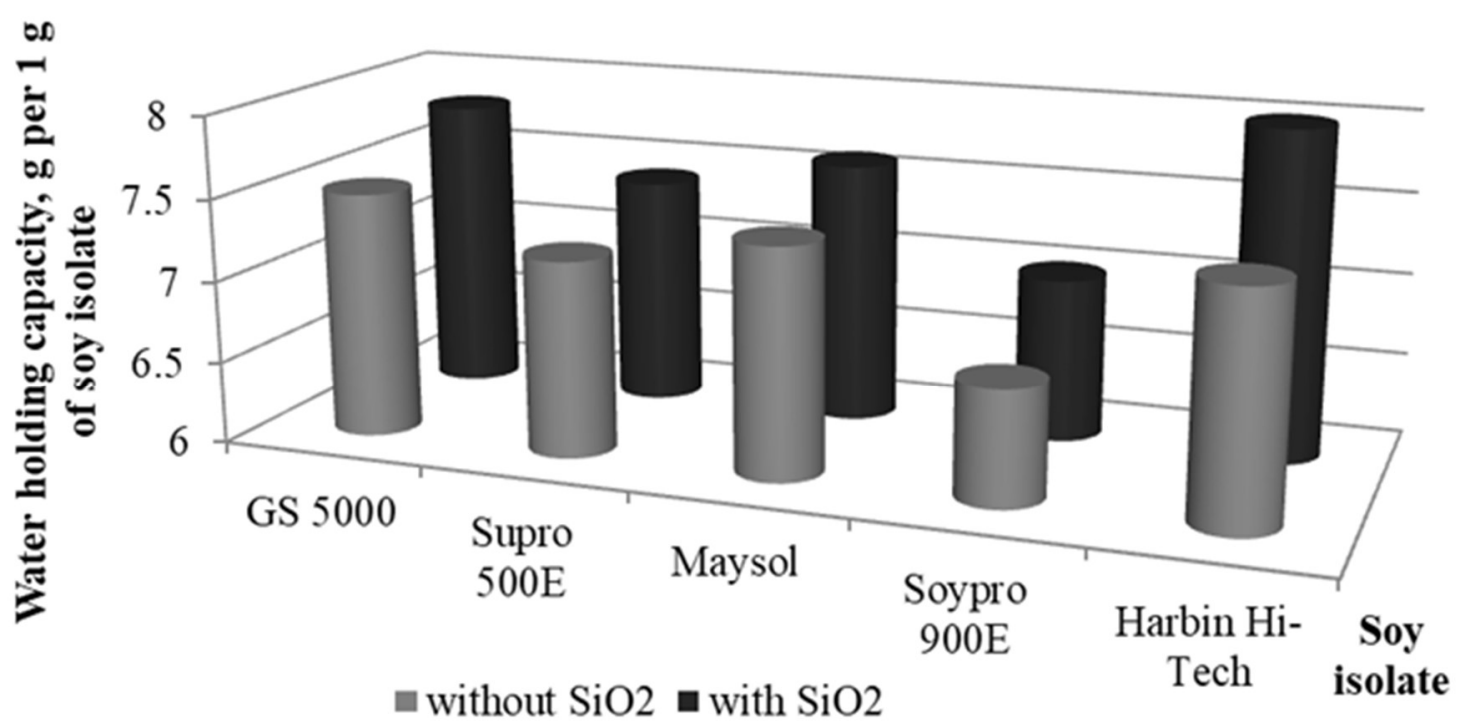

Notation: $\mathrm{SiO}_{2}$ - pyrogenic silica in the nanocomposite form (brand "Aerosil" A300), food additive E551.

Figure 2. Water-holding capacity of soy isolates of selected brands

In experimental samples of soy isolates of Maysol and Supro 500E brands there was noted a decrease in the rate of WHC by $3 \%$ compared to the rate of WAC. This indicated a partial loss of water binding capacity due to heat treatment. The introduction of silica to experimental samples of protein preparations showed a positive effect in relation to the indicator of WHC (increase by 3-8\%). The greatest effect was observed when interacting nanocomposite with soy isolate of Harbin Hi-Tech.

The established ability of soy isolates to absorb and hold water molecules was mainly due to the predominant amount of globular proteins, which showed a high ability to hydrate, provide high solubility, viscosity of experimental systems and they were characterized by high functional and technological properties (FTP): water-binding, fat-absorbing and emulsifying abilities, were able to form gels, structured matrices, stabilize emulsions, and also have high solubility, salt and heat resistance. This is one of the indicators which helps to combine their physical characteristics with raw meat materials. Due to the complex of properties, soy isolates remain one of the best protein preparations for the production of meat products. 